\title{
Effect of Anionic Polyacrylamide on the Structural Stability of Thickened Tailings Slurry in Pipeline Transportation
}

\author{
Shi Wang, ${ }^{1}$ Shuai Li $\left(\mathbb{D},{ }^{2}\right.$ Jian-chun Qin, ${ }^{3}$ Guang-zhe Xiao, ${ }^{1}$ Guo-chun Yang, ${ }^{1}$ and Xiao Feng ${ }^{1}$ \\ ${ }^{1}$ School of Resources and Environmental Engineering, Jiangxi University of Science and Technology, Ganzhou 341000, China \\ ${ }^{2}$ School of Resources and Safety Engineering, Central South University, Changsha 410083, China \\ ${ }^{3}$ Department of Personnel, Guangxi University of Science and Technology, Liuzhou 545006, China
}

Correspondence should be addressed to Shuai Li; 15200826420@163.com

Received 18 December 2017; Revised 6 March 2018; Accepted 21 March 2018; Published 26 April 2018

Academic Editor: Jun Liu

Copyright (C) 2018 Shi Wang et al. This is an open access article distributed under the Creative Commons Attribution License, which permits unrestricted use, distribution, and reproduction in any medium, provided the original work is properly cited.

Taking the superfine tailings slurry (STS), fine tailings slurry (FTS), and unclassified tailings slurry (UTS) of a gold mine as examples, a series of laboratory shear tests were conducted to investigate the effect of anionic polyacrylamide (APAM) on the structural stability of the thickened tailings slurry in pipeline transportation. Experimental results showed that the FTS and UTS had shear-thinning and shear-thickening characteristics in the constant shear tests, respectively. After addition of APAM, when the shear rate was $30 \mathrm{~s}^{-1}$, standard deviations of apparent viscosity of FTS, UTS, and STS were 66.67\%, 61.40\%, and 35.33\% lower, respectively. APAM enhances the strength of the flocculent structures, inhibits the hindered settling of the coarse-particle tailings, improves the structure stability of the solid particles on the structural plane, and assists pipeline transportation of the thickened tailings slurry.

\section{Introduction}

The pipeline transportation of tailings slurries has been a fast, environment-friendly, and economic choice for many mines around the world. The tailings slurries usually contain significant fractions of fine and coarse particles, causing them to exhibit non-Newtonian flow behavior and high frictional pressure gradients [1]. Due to the high capital and operation costs of positive displacement pumps for transporting tailings, it is of great significance to optimize the properties of tailings slurries so that they are sufficiently pumpable and flowable.

Flocculation is an important stage in the filtered tailings disposal process and is a necessary procedure in tailings thickening to enable the rapid settling of fine tailings particles [2]. Commonly used flocculants in tailings thickening include inorganic flocculants, organic polymer flocculants, microbial flocculants, and coagulant agents [3]. Flocculation is a complex physical and chemical reaction and involves charge neutralization, amphipathic adsorption, and selective agglomeration [4]. As a result, most of the flocculants bond with tailings particles and exist in the thickened tailings slurry, which changes the internal structures and affects the rheological characteristics of the slurry during pipeline transportation. Therefore, investigation into the mechanism of the flocculent effect on the characteristics of the thickened tailings slurry is important in order to complete its pipeline transportation theory.

In previous studies, the effects of flocculants on structural stability were ignored, and thickened tailings slurries were simplified as Bingham plastic fluid in pipeline transportation, whose flow properties were time-independent [5]. However, an increasing number of studies have found that this does not appear to be the case. Pornillos found that the yield stress and viscosity of Pd-Zn thickened tailings slurry decrease as the shear time increases and eventually stabilize [6]. Autier analyzed the effect of polycarboxylate on particle dispersion in cement paste using scanning electron microscopy and laser granulometry [7]. Yang et al. evaluated the dynamic damage and recovery process of flocculent structures and derived a high-precision time-varying hydraulic gradient model [8]. The above studies have achieved significant breakthroughs in exploring the effect of flocculants on the rheological characteristics of thickened tailings 
slurries. However, the effect of flocculants on the structural stability of thickened tailings slurries in pipeline transportation still needs further exploration.

Anionic polyacrylamide (APAM) is a widely used organic polymer flocculent in tailings thickening and shows good performance and high efficiency at low cost, particularly in the treatment of fine particles $[9,10]$. For thickened tailings slurries in pipeline transportation, groups of shear tests were conducted, and the variation curves of rheological parameters were obtained. Fitted curves for flocculent structures against the apparent viscosity were plotted, empirical expressions for these curves were calculated by regressive analysis, and the effect of APAM on the structural stability of thickened tailings slurries was analyzed.

\section{Experiments}

2.1. Materials. The material used in this study was the unclassified tailings slurry (UTS) disposed directly from a gold mine. The particle size distribution was analyzed using laser granulometry (Winner, China). A hydrocyclone can classify or separate solid grain from liquid and is widely used in metal mines [11]. Using a hydrocyclone, we obtained the superfine tailings slurry (STS) from the overflow and the fine tailings slurry (FTS) from the underflow. All three tailings slurries contained a specific amount of fine particles. STS was classified as superfine as $55 \%$ of the content was smaller than $19 \mu \mathrm{m}$. The UTS and FTS were classified as fine as the contents of particles smaller than $37 \mu \mathrm{m}$ were $38.21 \%$ and $54.82 \%$, respectively.

APAM used in this study was purchased from Xinyu Chemical Co., Ltd., Zhengzhou, China. APAM with an ionizability of $30 \%$ and molecular weight of 12 million Dalton showed excellent adaptability to fine tailings and was selected as the flocculent additive. The APAM had a charge density of APAM $0.19 \mathrm{mmol} / \mathrm{g}$, and the molecular structure is given in Figure 1 [12].

The positively charged tailings are neutralized by anions after the APAM is uniformly mixed, which weakens the strong repulsive interactions of the tailings [13]. The active groups and the colloids on the polymer chain connect via ionic bonds, hydrogen bonds, and electrostatic attraction, forming flocs by bridging and finally developing into flocculent structures [14]. Thickened tailings slurries in pipeline transportation form flocculent structures that are unstable and can not only be stretched or damaged by the continuous shearing force from the pipe wall but also lapped or recombined by bridging [15].

2.2. Experimental Procedure. After a series of static flocculating tests in the laboratory, the optimal APAM dosages of STS, UTS, and FTS were $50 \mathrm{~g} \cdot \mathrm{t}^{-1}, 40 \mathrm{~g} \cdot \mathrm{t}^{-1}$, and $25 \mathrm{~g} \cdot \mathrm{t}^{-1}$, respectively. The optimal APAM solution was evenly mixed with the tailing slurry in advance, and the thickened tailings slurry was obtained in the underflow of measuring cylinders. The underflow mass concentration of thickened STS, UTS, and FTS was 53\%, 60\%, and 66\%, respectively.

The HAAKE VT550 rotational viscometer, which was highly accurate in recording slight changes, was used for the laboratory shear tests [16]. The six prepared slurries,

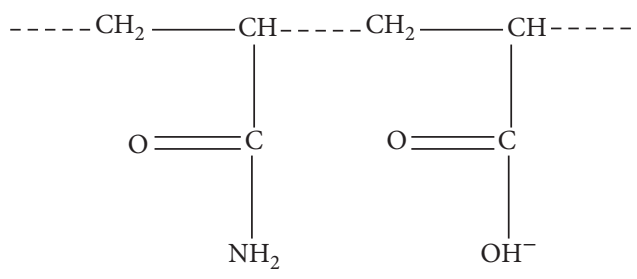

Figure 1: Molecular structure of APAM.

thickened STS, UTS, and FTS with optimal APAM dosages or without APAM addition, were placed in $500 \mathrm{~mL}$ beakers with a total mass of approximately $900 \mathrm{~g}$. The beakers were at room temperature for constant shear rheological testing. According to the common shear rate provided by the pipe wall in pipeline transportation, the shear rates were set at 10 , 30,50 , and $70 \mathrm{~s}^{-1}$, the shearing time was $600 \mathrm{~s}$, and shearing data were recorded every $6 \mathrm{~s}$.

By using the Zetasizer Nano-ZEN3600, the zeta potential tests were done with optimal APAM dosages or without APAM addition on $100 \mathrm{~mL}$ of the six prepared slurries. After being mixed with a magnetic stirrer at $500 \mathrm{rpm}$ for $15 \mathrm{~min}$ in a $125 \mathrm{~mL}$ beaker with an internal diameter of $5 \mathrm{~cm}$, the electrophoretic mobility measurements were done on samples collected during mechanical mixing.

2.3. Definitions. The structural stability of thickened tailings slurry is highly associated with the composition of its grain diameters. Considering that the changes in apparent viscosity in shear tests are a consequence of different particle sizes, these can be seen as the main indicator of structural stability. $\Delta \eta_{\mathrm{J} t}$ is defined as the quantity of flocculants that affects the apparent viscosity and can be expressed as

$$
\Delta \eta_{\mathrm{J} t}=\eta_{\mathrm{J} t}-\eta_{t}
$$

where $\eta_{\mathrm{J} t}(\mathrm{~Pa} \cdot \mathrm{s})$ is the apparent viscosity after flocculent addition at time $t$ and $\eta_{t}(\mathrm{~Pa} \cdot \mathrm{s})$ is the apparent viscosity before flocculent addition at time $t$.

The regression analysis of $\Delta \eta_{\mathrm{J} t}$ obtained from the tests can generate its fitting function $\Delta \eta_{\mathrm{JC} t}$, and the quantity of flocculants that affects the apparent viscosity, $\Delta \eta_{\mathrm{JCb}}$, can be expressed as

$$
\Delta \eta_{\mathrm{JCb}}=\lim _{t \rightarrow \infty} \Delta \eta_{\mathrm{JC} t}
$$

Standard deviations $\sigma$ and $\sigma_{\mathrm{J}}$ were used to express the structural stability of thickened tailings slurry before and after flocculent addition and is described in the following equation:

$$
\begin{array}{r}
\sigma=\sqrt{\frac{1}{99} \sum_{t=6}^{100}\left(\left|\eta_{\mathrm{C} t}-\eta_{t}\right|-\overline{\left|\eta_{\mathrm{C} t}-\eta_{t}\right|}\right)^{2}}, \\
\sigma_{\mathrm{J}}=\sqrt{\frac{1}{99} \sum_{t=6}^{100}\left(\left|\eta_{\mathrm{J} C t}-\tau_{\mathrm{J} t}\right|-\overline{\left|\eta_{\mathrm{JC} t}-\eta_{\mathrm{J} t}\right|}\right)^{2}}, \\
t=6,12, \ldots, 600,
\end{array}
$$




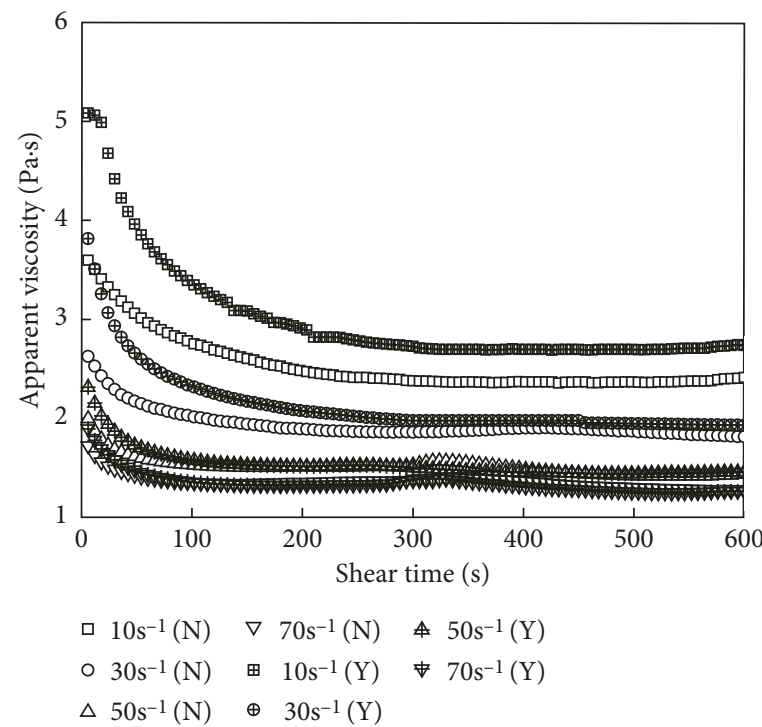

(a)

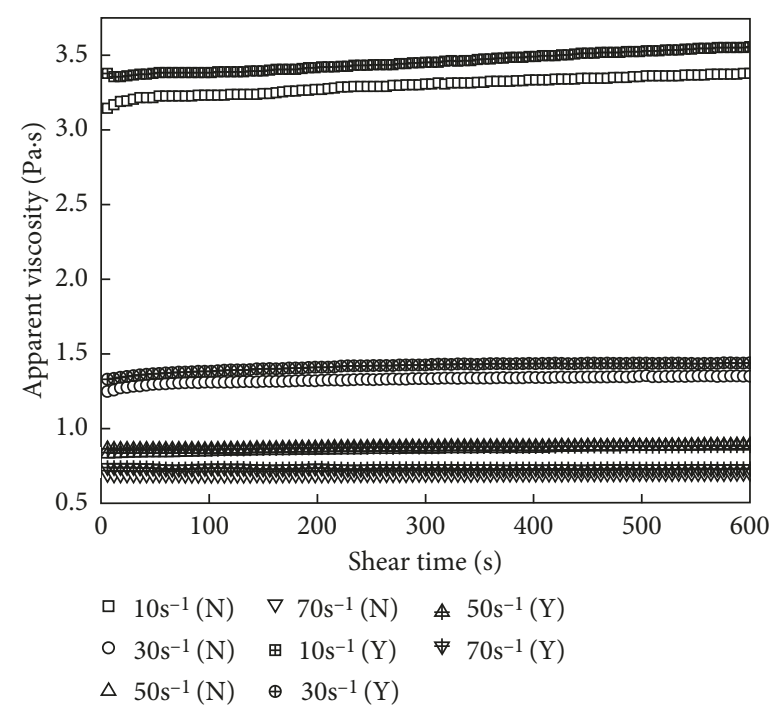

(b)

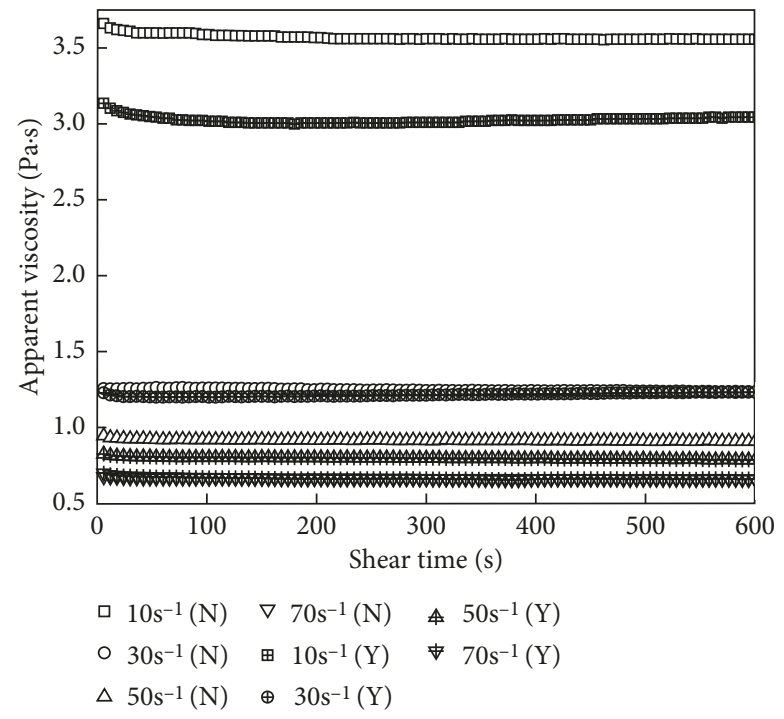

(c)

FIGURE 2: Changes of apparent viscosity: (a) FTS; (b) UTS; (c) STS (N means no APAM addition; Y means with optimal APAM addition).

where $\eta_{\mathrm{C} t}$ and $\eta_{\mathrm{JCt}}(\mathrm{Pa} \cdot \mathrm{s})$ are the apparent viscosities of the corresponding fitting functions before and after flocculent addition at time $t$, respectively and $\eta_{t}$ and $\eta_{\mathrm{J} t}(\mathrm{~Pa} \cdot \mathrm{s})$ are the measured apparent viscosities before and after flocculent addition at time $t$, respectively. If $\sigma_{\mathrm{J}}>\sigma$, the flocculent structures reduce the structural stability; if $\sigma_{\mathrm{J}}<\sigma$, the flocculent structures enhance the structural stability.

The Zetasizer Nano uses electrophoresis to determine this potential. The electrophoretic mobility is related to the zeta potential of the particles by the Henry equation, Ohshima's approximation, and Smoluchwski's formula $[17,18]$ :

$$
\zeta=\mu_{e} \frac{\eta}{\varepsilon} \frac{1}{f(k \cdot r)}
$$

where $\zeta$ is the zeta potential $(\mathrm{mV})$ and $f(k \cdot r)$ is the Henry correction factor. It depends on the size of the particles, their form factor, and the ionic strength of the environment by taking into account the thickness of the diffuse layer $(1 / k)$.

\section{Results and Discussion}

3.1. Results of Shear Tests. The dependence of the apparent viscosity of tested slurries on time was obtained and is shown in Figure 2. The properties of these slurries were significantly different from each other. As we can see from Figure 2(a), the FTS showed shear-thinning characteristics in the constant shear tests. When the shear rate was $10 \mathrm{~s}^{-1}$, the apparent viscosity of FTS with APAM addition decreased from 5.05 Pa.s to $2.73 \mathrm{~Pa} \cdot \mathrm{s}$, while that of FTS without APAM addition decreased from $3.72 \mathrm{~Pa} \cdot \mathrm{s}$ to $2.33 \mathrm{~Pa} \cdot \mathrm{s}$. They then gradually stabilized and acquired steady values. Similar behaviors were observed at other shear rates. However, the UTS showed shear-thickening characteristics, as its apparent 


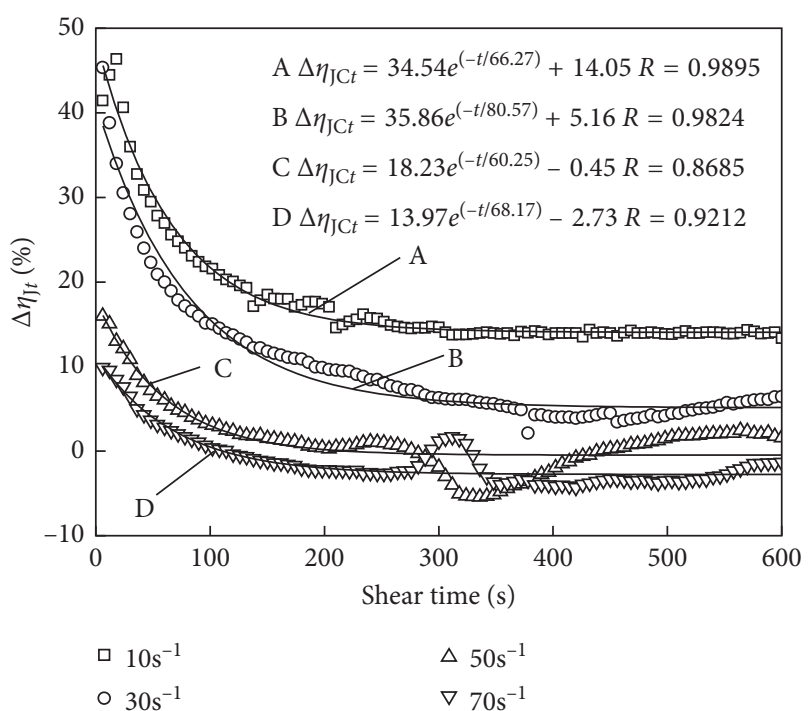

(a)

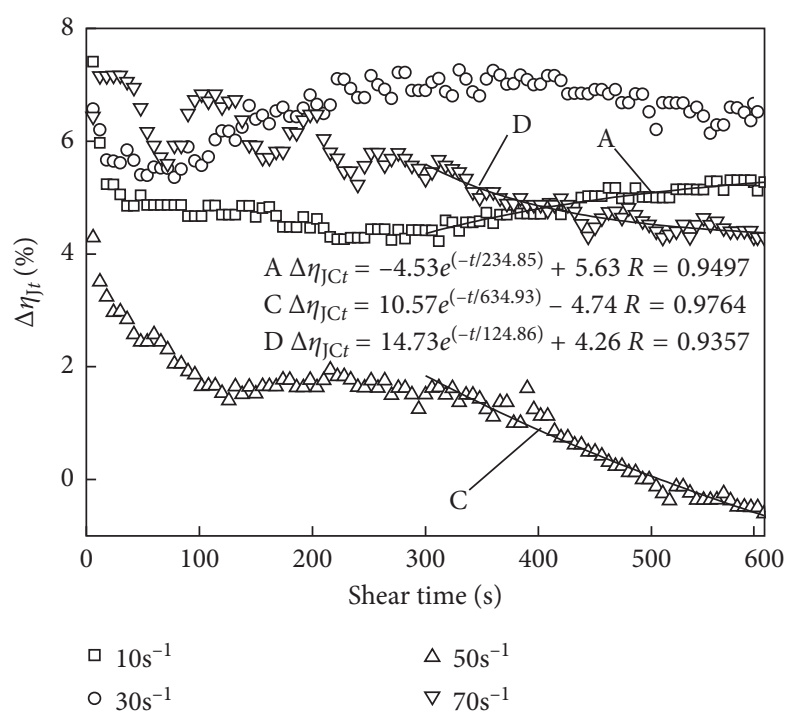

(b)

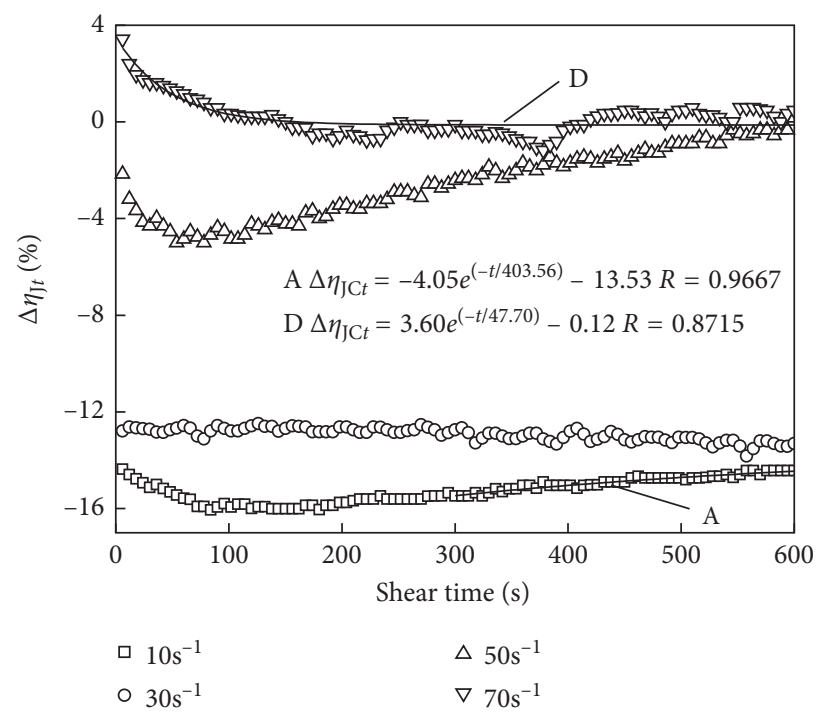

(c)

FIGURE 3: Varying tendency of $\Delta \eta_{\mathrm{JCt}}$ with shear time: (a) FTS; (b) UTS; (c) STS.

viscosity increased gradually with shear time (Figure 2(b)). The increasing range of apparent viscosity was $5.1-7.4 \%$ when the shear rate was $10 \mathrm{~s}^{-1}$, and it decreased to about $1 \%$ when the shear rate was $70 \mathrm{~s}^{-1}$. In addition, the apparent viscosity of STS was relatively stable in the constant shear tests as its range was within $\pm 2 \%$ (Figure $2(\mathrm{c})$ )).

3.2. Effect of APAM on $\triangle \eta_{\mathrm{J} t}$. Combined with the apparent viscosity-time curves, the dependence of the relative variation $\Delta \eta_{\mathrm{J} t}$ of slurries with addition of APAM was obtained. The regression analysis provided the fitting curves of $\Delta \eta_{\mathrm{JC} t}$ at different shear rates (Figure 3 ). Considering that the partial data were relatively discrete in the $0 \sim 300 \mathrm{~s}$ segment, some curves were regressed from the 300 600 s segment.

As can be seen from Figure $3(\mathrm{a}), \Delta \eta_{\mathrm{J} t}$ of FTS decreased gradually with the shear time, and the greater the shear rate, the lower the decline of $\Delta \eta_{\mathrm{J} t}$ is. For example, when the shear rate was $10 \mathrm{~s}^{-1}, \Delta \eta_{\mathrm{Jt}}$ decreased from $41.43 \%$ to the stabilized value of $13.34 \%$, while $\Delta \eta_{\mathrm{J} t}$ decreased by only $11.20 \%$ when the shear rate was $70 \mathrm{~s}^{-1}$. However, $\Delta \eta_{\mathrm{J} t}$ of UTS showed relatively complex tendency to vary. When the shear rate was $50 \mathrm{~s}^{-1}, \Delta \eta_{\mathrm{I} t}$ decreased rapidly from $4.29 \%$ to $-0.61 \%$ (Figure 3(b)), while the variation of $\Delta \eta_{\mathrm{J} t}$ showed no obvious pattern at other shear rates. For STS, $\Delta \eta_{\mathrm{J} t}$ increased after slightly decreasing. When the shear rate was $10 \mathrm{~s}^{-1}, \Delta \eta_{\mathrm{J} t}$ decreased from $-14.37 \%$ to $-16.04 \%$ and then slowly increased to the stabilized value of $-14.43 \%$, while $\Delta \eta_{\mathrm{J} t}$ fluctuated within $-12.93 \pm 1 \%$ with a shear rate of $30 \mathrm{~s}^{-1}$ (Figure $3(\mathrm{c})$ ).

3.3. Effect of APAM on $\Delta \eta_{J C b}$. The stabilized values of $\Delta \eta_{\mathrm{JCb}}$ at different shear rates were obtained from the limit value of $\Delta \eta_{\mathrm{JC} t}$ from fitting curves, as shown in Figure 4.

APAM made the apparent viscosity of FTS change from a positive to a negative effect. $\Delta \eta_{\mathrm{JCb}}$ decreased from $14.05 \%$ 


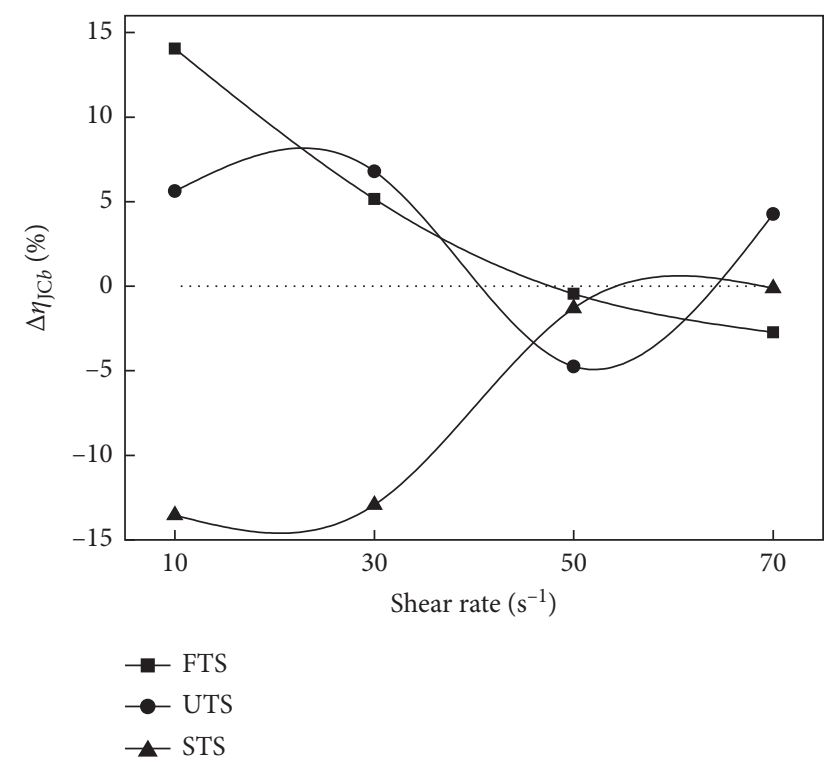

FIGURE 4: Varying tendency of $\Delta \eta_{\mathrm{JCb}}$ with shear rate.

to $-2.73 \%$ when the shear rate increased from $10 \mathrm{~s}^{-1}$ to $70 \mathrm{~s}^{-1}$. For UTS, APAM had a complex effect on the values of $\Delta \eta_{\mathrm{J} C b}$, causing them to rise initially, then decrease, and rise again. The tendency of $\Delta \eta_{\mathrm{JCb}}$ to vary for STS rose gradually with the shear rate and approached zero when the shear rate was $70 \mathrm{~s}^{-1}$.

3.4. Effect of APAM on $\sigma$. The addition of APAM caused the long molecular chains to affect the relative movements of tailings particles, which further affected the structural stability of the tailings slurry [19]. By calculating the standard deviations of the apparent viscosity in the shear tests, the dependence of apparent viscosity fluctuation on time, before and after addition of APAM, reflected the changes in structural stability. From Figure 2 and (3), the standard deviations, $\sigma$, before and after addition of APAM, were calculated (Figure 5).

As we can see from Figure 5, $\sigma$ of the thickened tailings slurry decreased gradually with increasing shear rate. When the shear rate increased from $10 \mathrm{~s}^{-1}$ to $70 \mathrm{~s}^{-1}, \sigma$ of STS decreased from $0.0734 \mathrm{~Pa} \cdot \mathrm{s}$ to $0.0071 \mathrm{~Pa} \cdot \mathrm{s}$, and $\sigma$ of FTS and UTS showed similar behaviors. After addition of APAM addition, the $\sigma_{\mathrm{J}}$ values decreased and showed better structural stability. For example, when the shear rate was $30 \mathrm{~s}^{-1}, \sigma_{\mathrm{J}}$ values for FTS, UTS, and STS were $66.67 \%, 61.40 \%$, and $35.33 \%$ lower, respectively. Given the above condition, the fluctuation of the apparent viscosity of slurries decreased and the structural stability improved after addition of APAM.

\section{Mechanism Analysis}

The hindered settling of coarse particles in tailings slurries can cause instability in transportation, for example, pipe blockage and erosive wear [20]. In addition to the effects of gravity and buoyancy from these coarse particles, mechanical and media resistance from other particles is also

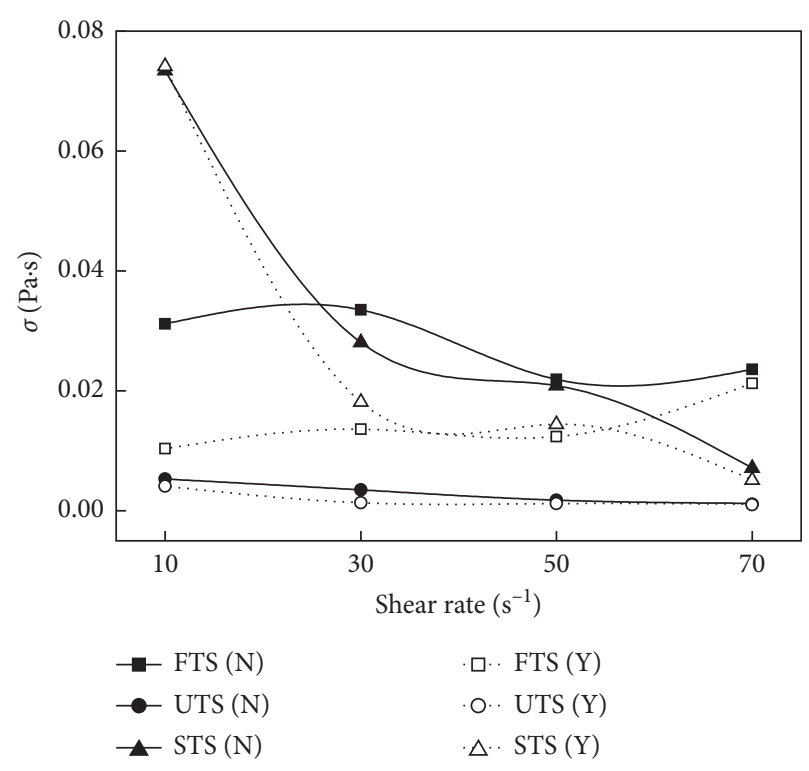

FIGURE 5: Varying tendency of $\sigma$ with shear rate ( $\mathrm{N}$ means no APAM addition; Y means with optimal APAM addition).

observed [21]. After the addition of APAM, the structural strength of long molecular chains is high, and the compressibility of bond water is low. The relative movements between particles are limited, and the relative stability of solid particles on the structural plane increases. As a result, there is a more even distribution of particles in the vertical plane, the grain structure has improved resistance to dislocation deformation, and the hindered settling rate of coarse particles decreases. The mechanism of action of APAM on the structural stability of the thickened tailings slurry is shown in Figure 6.

Before addition of APAM, parts of the fine-particle tailings form small aggregates under the weak effect of compressed electrical double layers. A large amount of free water exists in the gaps, and the flocculent structures are very fragile (Figure 6(a)). After addition of APAM, long molecular chains of APAM are absorbed onto the surface of the fine particles and form large, strong flocculent structures [22]. Then, free water is converted into bound water and inhibits the hindered settling of the coarse particles and flocculent structures (Figure 6(b)). As a result, the structural stability of the thickened tailings slurry is improved, and the fluctuation of the apparent viscosities of slurries is decreased. Under continued shearing force from the pipe wall in pipeline transportation, small, weak aggregates are easily damaged, which decreases the structural stability of the tailings slurry (Figure 6(c)). Despite the damage caused to flocculent structures from shear stress, the bonding force between active groups on the polymer chain and the fine tailings particles is strong, and the reduction in structural strength is less than that without addition of APAM. Therefore, the flocculent structures can still inhibit the hindered settling of coarse particles and improve the structural stability of the thickened tailings slurry (Figure 6(d)).

Results of the zeta potential tests are shown in Figure 7. As the tested tailings slurries are both abundant in electropositive 
(a)

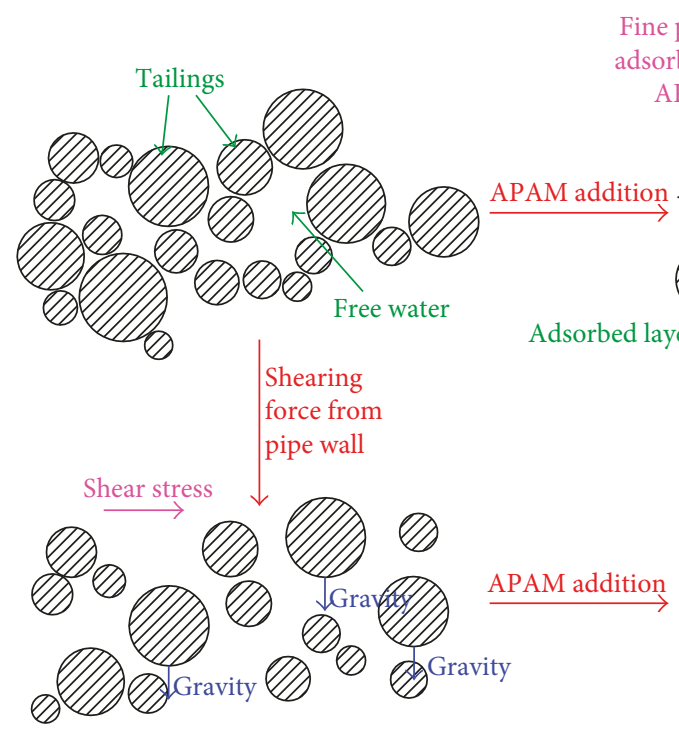

(c) (b)

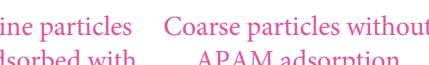

APAM adsorption
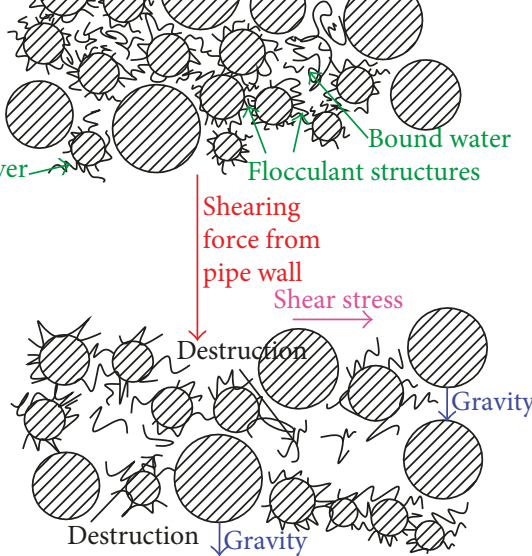

(d)

FIgURE 6: Evolution diagram of the action mechanism of APAM: (a) without shear stress and APAM addition; (b) without shear stress but with APAM addition; (c) under shear stress but without APAM addition; (d) under shear stress and with APAM addition.

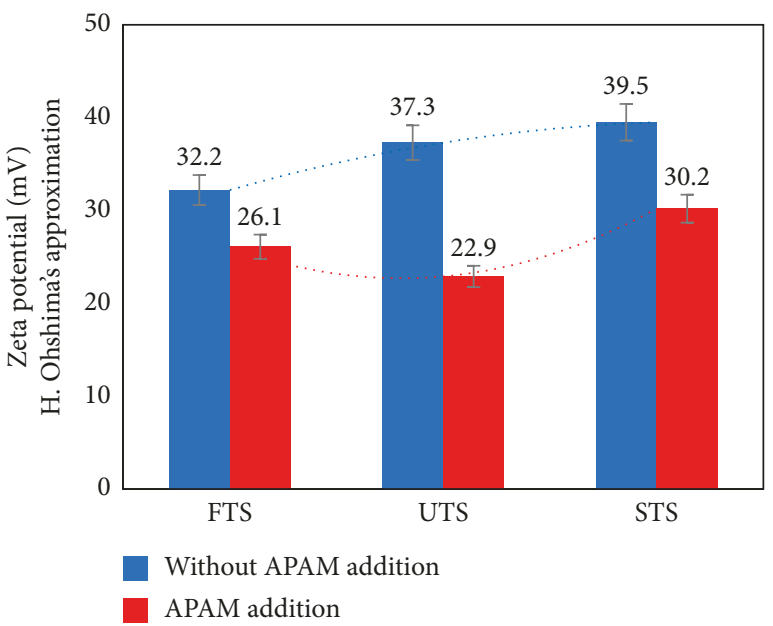

FIGURE 7: Results of the zeta potential tests based on H. Ohshima's approximation.

slimes and ultrafine tailings, like charges repel, the strong electrostatic repulsion between the ultrafine particles cause high zeta potentials. After APAM was added and uniformly mixed, the strong positively charged ultrafine particles will be neutralized by anions. As a result, the strong repulsive interactions will be weak, the thick hydration shells will be thin, and the zeta potentials will be low. Then, the tailings slurry with APAM addition shows better structure stability than before.

\section{Conclusions}

(1) Charge neutralization and bridging constitute the main mechanisms of action of APAM. Flocculent structures can not only be lapped and recombined through flocculent bridging but also stretched or damaged by shearing force from the pipe wall. Therefore, thickened tailings slurries in pipeline transportation are consistent with a time-varying rheological model as opposed to a Bingham model.

(2) After addition of APAM, with a shear rate of $10 \mathrm{~s}^{-1}$, the apparent viscosity of FTS decreased from $5.05 \mathrm{~Pa} \cdot \mathrm{s}$ to $2.73 \mathrm{~Pa} \cdot \mathrm{s}$, the increasing range of UTS was $5.1-7.4 \%$, and that of STS was relatively stable. FTS and UTS showed shear-thinning and shearthickening characteristics in the constant shear tests, respectively.

(3) $\sigma$ of the thickened tailings slurry decreased gradually as the shear rate increased. After addition of APAM, when the shear rate was $30 \mathrm{~s}^{-1}, \sigma_{\mathrm{J}}$ values for FTS, UTS, and STS were $66.67 \%, 61.40 \%$, and $35.33 \%$ lower, respectively. The fluctuation of the apparent viscosity of the slurries decreased, and the structural stability improved after addition of APAM.

(4) APAM enhanced the strength of the flocculent structures, inhibited the hindered settling of the coarse-particle tailings, improved the structural stability of the solid particles in the structural plane, and assisted pipeline transportation of the thickened tailings slurry.

\section{Conflicts of Interest}

The authors declare that they have no conflicts of interest.

\section{Acknowledgments}

The authors thank the financial supports from the National Key R\&D Program of China (2017YFC0804605), the Doctoral 
Startup Fund of Jiangxi University of Science and Technology (jxxjbs17011), and the National Natural Science Foundation of China (51304083).

\section{References}

[1] R. Jewell and A. Fourie, Paste and Thickened Tailings, A Guide, Australian Centre for Geomechanics, Perth, WA, Australia, 3rd edition, 2015.

[2] L. I. Shuai, X. Wang, Q. Zhang et al., "Dynamic experiments on flocculation and sedimentation of argillized ultrafine tailings using fly-ash-based magnetic coagulant," Transactions of Nonferrous Metals Society of China, vol. 26, no. 7, pp. 1975-1984, 2016.

[3] K. A. S. Meraz, S. M. P. Vargas, J. T. L. Maldonado et al., "Ecofriendly innovation for nejayote coagulation-flocculation process using chitosan: evaluation through zeta potential measurements," Chemical Engineering Journal, vol. 284, pp. 536-542, 2016.

[4] S. Li and X.-M. Wang, "Fly-ash-based magnetic coagulant for rapid sedimentation of electronegative slimes and ultrafine tailings," Powder Technology, vol. 303, pp. 20-26, 2016.

[5] X. Wang, J. Zhao, J. Xue et al., "Features of pipe transportation of paste-like backfilling in deep mine," Journal of Central South University of Technology, vol. 18, no. 5, pp. 1413-1417, 2011.

[6] E. U. Pornillos, "A technique for measuring the reduction of yield stress of thickened tailings," in Proceedings of the 14th International Seminar on Paste and Thickened Tailings, pp. 167-173, Perth, WA, Australia, April 2011.

[7] C. Autier, N. Azema, J. M. Taulemesse, and L. Clerc, "Mesostructure evolution of cement pastes with addition of superplasticizers highlighted by dispersion indices," Powder Technology, vol. 249, no. 11, pp. 282-289, 2013.

[8] L. Yang, S. Li, and X.-M. Wang, "Time-varying hydraulic gradient model of paste-like tailings in long-distance pipeline transportation," Advances in Materials Science and Engineering, vol. 2017, Article ID 5276431, 8 pages, 2017.

[9] R. Zhang, S. Yuan, W. Shi et al., "The impact of anionic polyacrylamide (APAM) on ultrafiltration efficiency in flocculation-ultrafiltration process," Water Science and Technology, vol. 75, no. 8, pp. 1982-1989, 2017.

[10] L. Feng, H. Zheng, B. Gao et al., "Fabricating an anionic polyacrylamide (APAM) with an anionic block structure for high turbidity water separation and purification," RSC Advances, vol. 7, no. 46, pp. 28918-28930, 2017.

[11] P. Gonzales, O. Felix, C. Alexander, E. Lutz, W. Ela, and A. E. Sáez, "Laboratory dust generation and size-dependent characterization of metal and metalloid-contaminated mine tailings deposits," Journal of hazardous materials, vol. 280, pp. 619-626, 2014.

[12] S. H. Sadeghi, Z. Hazbavi, H. Younesi et al., "Trade-off between runoff and sediments from treated erosion plots and polyacrylamide and acrylamide residues," Catena, vol. 142, pp. 213-220, 2016.

[13] H.-E. Ries and B.-L. Meyers, "Flocculation mechanism: charge neutralization and bridging," Science, vol. 160, no. 3835, pp. 1449-1450, 1968.

[14] E Antunes, F.-A. Garcia, P Ferreira, A Blanco, C. Negro, and M.-G. Rasteiro, "Modelling PCC flocculation by bridging mechanism using population balances: effect of polymer characteristics on flocculation," Chemical Engineering Science, vol. 65, no. 12, pp. 3798-3807, 2010.
[15] E.-A. Toorman, "Modelling the thixotropic behaviour of dense cohesive sediment suspensions," Rheologica Acta, vol. 36, no. 1, pp. 56-65, 1997.

[16] J. W. Zhao, X. M. Wang, K. Peng, and S. Li, "Utilization of foaming technology in cemented paste backfill of high-mud superfine unclassified tailings," Advances in Materials Science and Engineering, vol. 2017, Article ID 6157869, 7 pages, 2017.

[17] M. Bizi, "Stability and flocculation of nanosilica by conventional organic polymer," Natural Science, vol. 4, no. 6, pp. 372-385, 2012.

[18] H. Ohshima, "A simple expression for Henry's function for the retardation effect in electrophoresis of spherical colloidal particles," Journal of Colloid and Interface Science, vol. 168, no. 1, pp. 269-271, 1994.

[19] T. Swift, L. Swanson, A. Bretherick et al., "Measuring poly (acrylamide) flocculants in fresh water using inter-polymer complex formation," Environmental Science: Water Research \& Technology, vol. 1, no. 3, pp. 332-340, 2015.

[20] X. Chen, J. Zhou, Q. Chen, X. Shi, and Y. Gou, "CFD simulation of pipeline transport properties of mine tailings threephase foam slurry backfill," Minerals, vol. 7, no. 8, p. 149, 2017.

[21] J. J. Derksen, "Simulations of hindered settling of flocculating spherical particles," International Journal of Multiphase Flow, vol. 58, no. 1, pp. 127-138, 2014.

[22] J. Su, C. J. Garvey, S. Holt, B. Wintherjensen, W. Batchelor, and G. Garnier, "Adsorption of cationic polyacrylamide at the cellulose-liquid interface: a neutron reflectometry study," Journal of Colloid and Interface Science, vol. 448, pp. 88-99, 2015. 


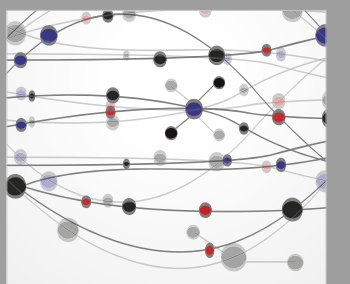

The Scientific World Journal
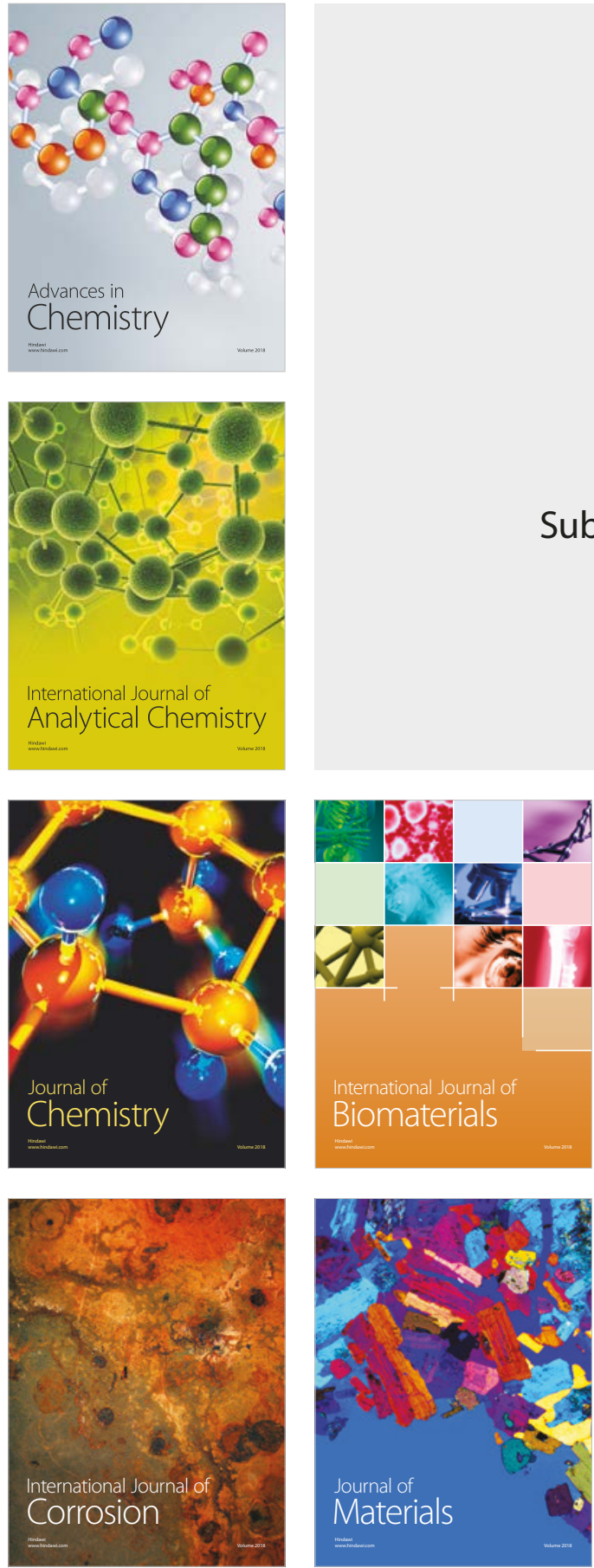

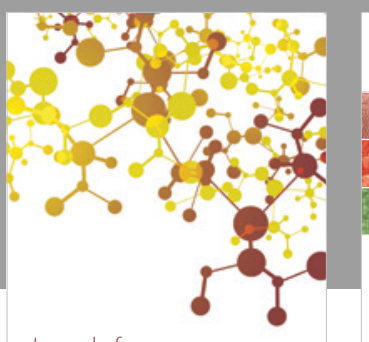

Journal of

Applied Chemistry
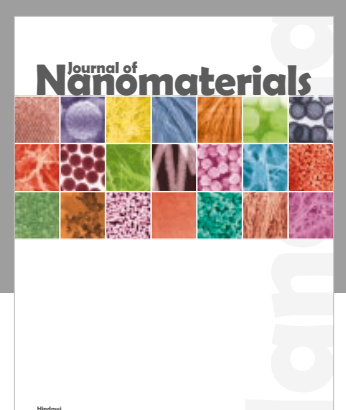

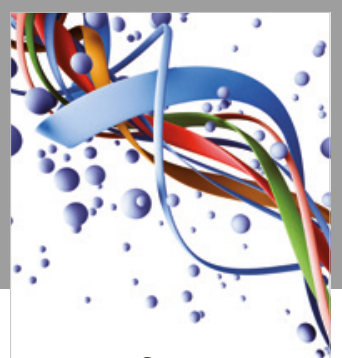

Scientifica

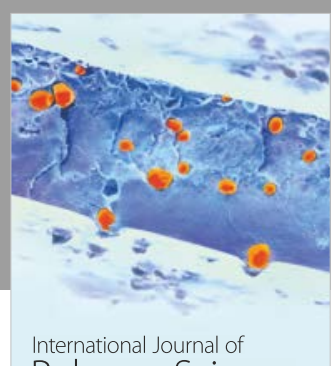

Polymer Science

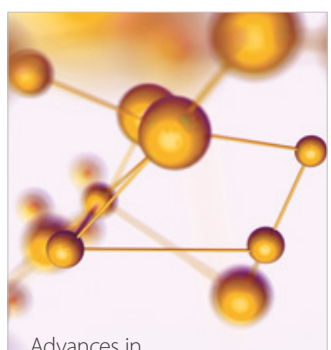

Physical Chemistry
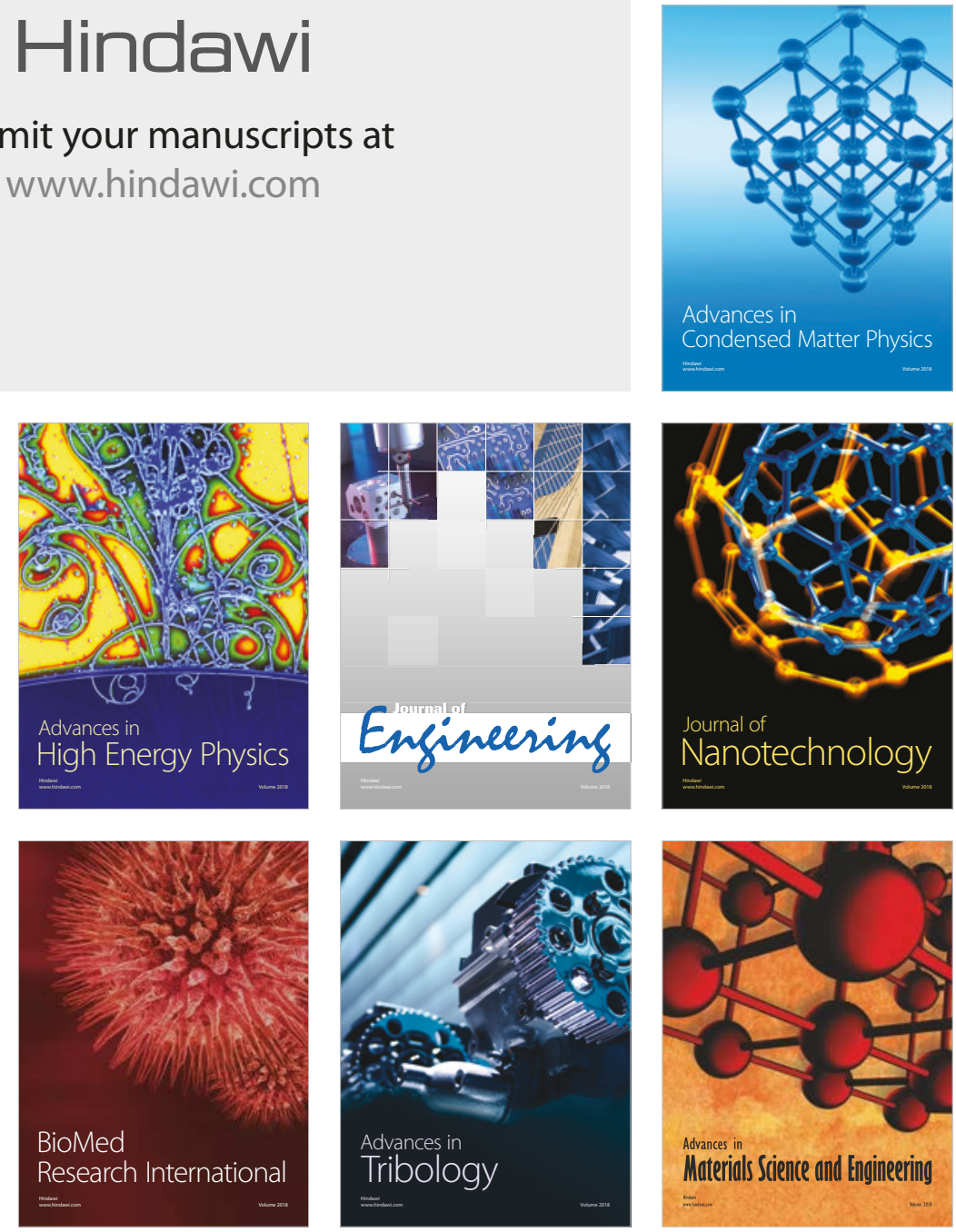